\title{
Photovoltaic Energy in Power Market
}

\author{
D.T. Ho, J. Frunt, Student Member, IEEE, J.M.A. Myrzik
}

\begin{abstract}
Photovoltaic (PV) penetration in the grid connected power system has been growing. Currently, PV electricity is usually directly sold back to the energy supplier at a fixed price and subsidy. However, subsidies should always be a temporary policy, and will eventually be terminated. A question is raised whether grid-connected PV generation will be more beneficial by making biddings in power markets than by supplying at a fixed price. An economic model of profit maximization for PV generation when joining power markets is proposed to answer the question. A simplified model is applied to simulate a case study of PV biddings in the Amsterdam Power Exchange (APX) spot market, using PV generation data from a standardized neighborhood PV installation. A Monte Carlo method is used to calculate penalty costs due to over-predicted irradiation. Also a Monte Carlo simulation is applied to survey a number of random imbalance capacities and corresponding prices within a Gaussian distribution by repeating the calculation loop. The sensitivity for prediction errors is examined by simulations with different unpredictability levels of solar irradiation. The outcome of the simulations is a value for the difference between the two revenues of PV generation when joining power markets and when supplying at a fixed price.
\end{abstract}

Index Terms-Photovoltaic power systems, Power system economics, Power generation economics, Power generation dispatch, Monte Carlo methods.

\section{INTRODUCTION}

$\mathrm{R}$ ecently electricity industry has experienced changes in several countries towards deregulation and more competitive markets. Under this condition, generation plants will try to maximize their own profits. Another important change is the appearance and growth of distributed generators, and many are based on renewable sources. The integration of distributed generation has been increasing significantly in many countries.

Among various technologies of sustainable energy sources, photovoltaic (PV) appears quite attractive for electricity generation because of its noiseless, no carbon dioxide emission when operating, scale flexibility and rather simple operation and maintenance. Currently, the cost of electricity generated by PV remains higher than by traditional power plants using fossil fuel. Hence, a subsidy for PV suppliers is applied in many countries to encourage electricity produced from sustainable energy. Currently, the PV electricity is usually directly sold back to the energy supplier at fixed price and subsidy. However, subsidy should always be a temporary policy, and will eventually be terminated. Hence, a question is

D.T. Ho, J. Frunt, and J.M.A. Myrzik are in Eindhoven University of Technology, Eindhoven, 5600MB, the Netherlands (e-mail: d.t.ho@student.tue.nl, j.frunt@tue.nl,j.m.a.myrzik@tue.nl). raised whether grid-connected PV generation will be more beneficial by making biddings in power markets than by supplying at a fixed price when there is no longer subsidy.

An advantage of PV is its property of generating electricity during peak period in daytime, when power market prices are usually higher than the fixed price. However, a disadvantage of $\mathrm{PV}$ is that it depends on irradiation which is not exactly predictable. The probability for PV not to deliver adequately as scheduled is obvious, and consequently, possible penalty costs are accounted when calculating the revenue for PV in power markets.

\section{ECONOMIC MODEL}

An optimization problem is proposed for autonomous networks in the day ahead market in [1]. An autonomous power network is the aggregation of producers and consumers presented in the overall power system as one unit [1]. An autonomous network dispatching optimization problem is formulated with penalty costs for each autonomous network to make optimal decisions in the market environment. A novel stochastic model for the generation companies to self-schedule and maximize their profits in a restructured electricity market is expressed in [2] with considering the probability that reserve market is called and generated.

The objective of PV suppliers to participate in energy and imbalance system is to maximize the profit $(1-5)$, subject to all related constraints, which are concerning system transmission limits, PV capacity limits, and solar irradiation.

Profit maximization:

$\underset{E, I}{\operatorname{Maximize}(\mathrm{Pr})}$

Annual profit [€]:

$P r=R-C-P e$

Annual revenue $[€]$

$R=P_{E}(t) \cdot E(t)+k(t) \cdot P_{I}(t) \cdot I(t)$

Annual costs $[€]$

$C=(1-k(t)) \cdot C(E(t))+k(t) \cdot C(E(t)+I(t))$

Annual penalty costs $[€]$

$P e=P_{\Delta E}(t) \cdot \Delta E(t)+P_{\Delta I}(t) \cdot \Delta I(t)$

where:

$\mathrm{t}=[1,2, \ldots 8760]$ [hour $]$

E, I: generation supplied in Energy market, Imbalance system [MWh]

$\mathrm{P}_{\mathrm{E}}, \mathrm{P}_{\mathrm{I}}$ : predicted market prices at Energy market, Imbalance system [€/MWh]

$\mathrm{k}$ : estimated probability that imbalance power is called and generated by PV.

$\mathrm{C}(\mathrm{E}), \mathrm{C}(\mathrm{E}+\mathrm{I})$ : cost function of $\mathrm{PV}$ to produce $\mathrm{E}, \mathrm{E}+\mathrm{I}[€]$ 
$\mathrm{P}_{\Delta \mathrm{E}}, \mathrm{P}_{\Delta \mathrm{I}}$ : estimated penalty costs at Energy market, Imbalance system [€/MWh]

$\Delta \mathrm{E}, \Delta \mathrm{I}$ : estimated Energy, Imbalance that cannot be delivered as commitment [MWh]

\section{Power Market Situation In The NetherlandS}

The Dutch electricity market is a liberalized market, which means that all acceded parties are allowed to trade electricity. Two related power markets in the Netherlands are represented as follows.

\section{A. Amsterdam Power Exchange (APX) Market}

Next to the bilateral contracts, parties are allowed to trade in the Amsterdam Power Exchange (APX). This exchange is a day ahead market with biddings on an hourly base and price ladders. The advantage of trading via APX instead of trading via long term contracts is that the quantity and price of the bid only has to be defined one day ahead. In this way it enables player and anticipation on weather conditions and load predictions in a better way to the variable fuel sources such as renewable energy [3].

\section{B. Imbalance System}

This system is used to settle any existing imbalance in the grid. In the Netherlands, the transmission system operator settles the imbalance by dispatching available control capacity. Up to two hours in advance of the transaction, suppliers can make bids for regulating, reserve, and emergency power. Both for positive and negative imbalances markets exist. All suppliers receive an equal price when their capacity is dispatched [3].

\section{SimUlation}

\section{A. The Simplified Model}

A simplified economic model is implemented in a standardized neighborhood with $700 \mathrm{kWp}$ grid connected PV installation. The simplified model is applied for PV to attend the day ahead power market only, not the hourly intraday or the imbalance system. Therefore, the estimated probability that imbalance power called and the generation supplied in imbalance system are now zero, which means $\mathrm{k}=0, \mathrm{I}=0$ and $\Delta \mathrm{I}=0$. From the profit maximizing problem the simplified model becomes a profit calculation (6-9) and comparison between day ahead market participation and fixed price application.

$P r=R-C-P e$

$R=P_{E} \cdot E$

$C=C(E)$

$P e=P_{\Delta E} \cdot \Delta E$

\section{B. Input Data}

The APX daily price data with off-peak, peak and superpeak market clearing prices are provided by APX. The fixed price for off peak period is $159.80 € / \mathrm{MWh}$ and for peak period is $214.10 € / \mathrm{MWh}$.
Fig. 1 displays the off-peak, peak periods and a typical PV generation curve showing that PV generation duration covers partly the peak period in general.

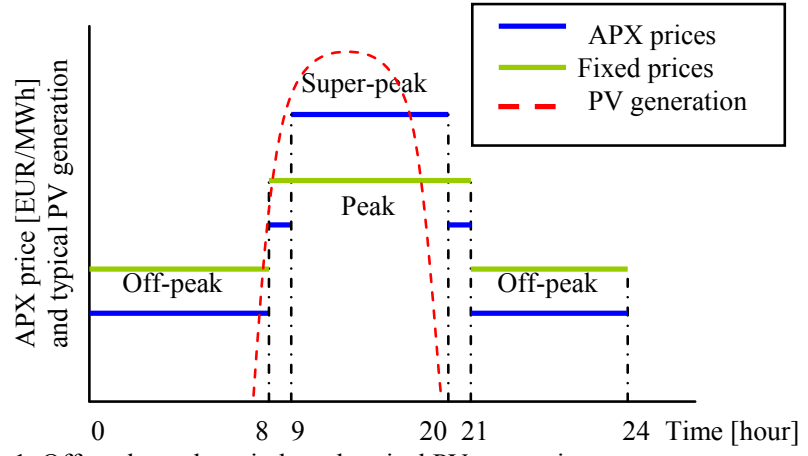

Fig. 1. Off-peak, peak periods and typical PV generation curve

\section{Revenue Calculation}

For the fixed price application, the selling electricity price of a supplier depends on the annual supply [4] and is shown in Table I.

Table I

Fixed price application

\begin{tabular}{|l|l|}
\hline \multicolumn{1}{|c|}{ Annual supply } & \multicolumn{1}{|c|}{ Selling price } \\
\hline For the first 3 MWh & $\begin{array}{l}\text { Fixed price (Offpeak: 159.80 } \\
€ / \mathrm{MWh} \text {, peak: } 214.10 € / \mathrm{MWh})\end{array}$ \\
\hline From 3 MWh to 5 MWh & $82 € / \mathrm{MWh}$ \\
\hline$>5 \mathrm{MWh}$ & $\begin{array}{l}\text { mean of APX price } \\
€ / \mathrm{MWh} \text { in 2006) }\end{array}$ \\
\hline
\end{tabular}

\section{Cost Calculation}

The installation costs of a PV system is about 3.30 to 4.50 $€ / \mathrm{Wp}$ and the electricity generation efficiency ranges from 1000 to $1200 \mathrm{kWh} / \mathrm{year} / \mathrm{kWp}$ for the Netherlands [5]. The operation and maintenance costs, the decommissioning costs and/or returns are assumed to be negligible. During the life time of PV system, the annualized installation cost is calculated and considered the yearly cost of PV generation.

\section{E. Penalty Calculation}

Penalty costs are applied to express the costs for nondelivered energy when PV joins power market since the PV irradiation cannot be predicted exactly. The maximum unpredictability is assumed to be $30 \%$ of the predicted values. The penalty costs for non-delivered PV energy is the market clearing price in the imbalance system.

The distribution of the deployment of the imbalance capacity is a Gaussian distribution with the mean of $-11 \mathrm{MW}$ and the standard deviation of $106 \mathrm{MW}$ in 2006 [3]. Moreover, the third order trend line, which is the stochastic relation between the imbalance capacity and the difference of imbalance price and APX price at every fifteen minutes in 2005 is as (10).

$\lambda\left(\mathrm{P}_{\mathrm{imb}}\right)=-6.1226 \cdot 10^{-7} \cdot\left(\mathrm{P}_{\mathrm{imb}}\right)^{3}+0.0020 \cdot\left(\mathrm{P}_{\mathrm{imb}}\right)^{2}+$ $0.1158 \cdot\left(\mathrm{P}_{\mathrm{imb}}\right)+15.3395$

$\lambda\left(\mathrm{P}_{\text {imb }}\right)$ : expected difference between imbalance price and

APX price [€/MWh]

$\mathrm{P}_{\mathrm{imb}}$ : imbalance capacity $[\mathrm{MW}]$ 
It is assumed that the stochastic relation between the imbalance power and the price difference at every hour in 2006 has the same function as at every fifteen minutes in 2005. Therefore, the above function is considered as the stochastic relation between the expected hourly imbalance power and the expected hourly price difference in 2006.

Monte Carlo method is applied to survey the varied range of the random imbalance capacities and prices by repeating the calculation loop. Random numbers generated within the mentioned above Gaussian distribution are assumed to be the total imbalance power in the whole system at every hour in 2006. From the hourly imbalance power and the trend line, the hourly system imbalance prices are obtained.

A similar Monte Carlo random loop is employed to calculate the non-delivered energy by using normal Gaussian distribution with maximum values as $\pm 15 \%$ of the predicted PV generation representing $30 \%$ of the predictable uncertainty. Penalty costs are calculated in (11).

$P e=\sum_{i=1}^{8760} P_{\Delta E}(i) \cdot \Delta E(i)$

where:

Pe: annual penalty costs $[€]$

$\mathrm{P}_{\Delta \mathrm{E}}(\mathrm{i})$ : hourly penalty price [€/MWh]

$\triangle \mathrm{E}$ : hourly non-delivered energy [MWh]

\section{RESULTS}

\section{A. PV Generation Profile}

The PV generation and daily APX prices in the first week of February, 2006 and in the third week of August, 2006 are displayed in Fig. 2 and Fig. 3, representing the PV generation and APX prices in winter and summer.

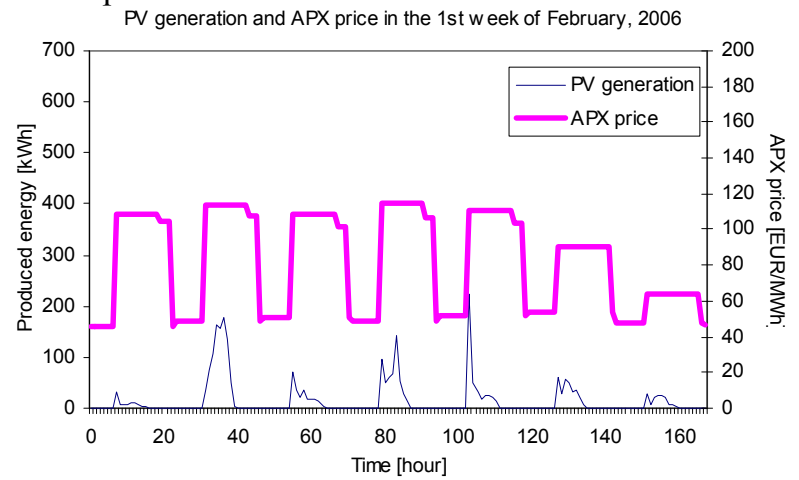

Fig. 2. PV generation and APX price in the first week of February 2006, representing typical PV generation and APX price profiles in winter.

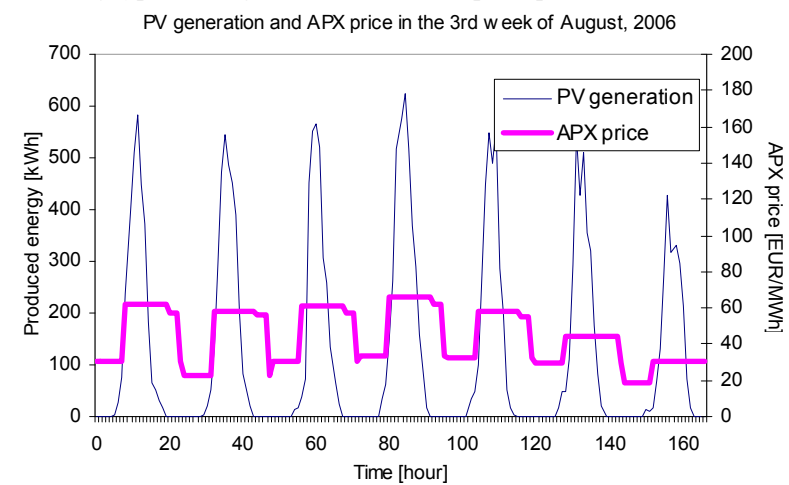

Fig. 3. PV generation and APX price in the third week of August 2006, representing typical PV generation and APX price profiles in summer.

\section{B. PV Generation versus prices}

Fig. 4 shows the hourly PV productions and their APX prices at the red scattered points. The fixed price at 214.10 $€ / \mathrm{MWh}$ (dotted line) is attractive for annual PV production less than $3 \mathrm{MWh}$, which can be generated by a $2.80 \mathrm{kWp} \mathrm{PV}$ module at the average yield of $1100 \mathrm{kWh} / \mathrm{kWp}$ in the Netherlands [5]. For PV power plants with yearly PV generation greater than $3 \mathrm{MWh}$, the fixed prices decrease to $82.00 € / \mathrm{MWh}$ (dash line) and then to the APX average price $58.88 € / \mathrm{MWh}$ (solid line). The linear fit line of PV generation versus APX price (bold line) shows the tendency of PV generation versus price. The correlation coefficient between APX prices and PV generation is 0.25 , which is positive and shows that the higher prices encourage the production. Hence, bidding in APX market can be expected to be more beneficial than supplying at a fixed price as long as the variable prices are mostly higher than the applied fixed price.

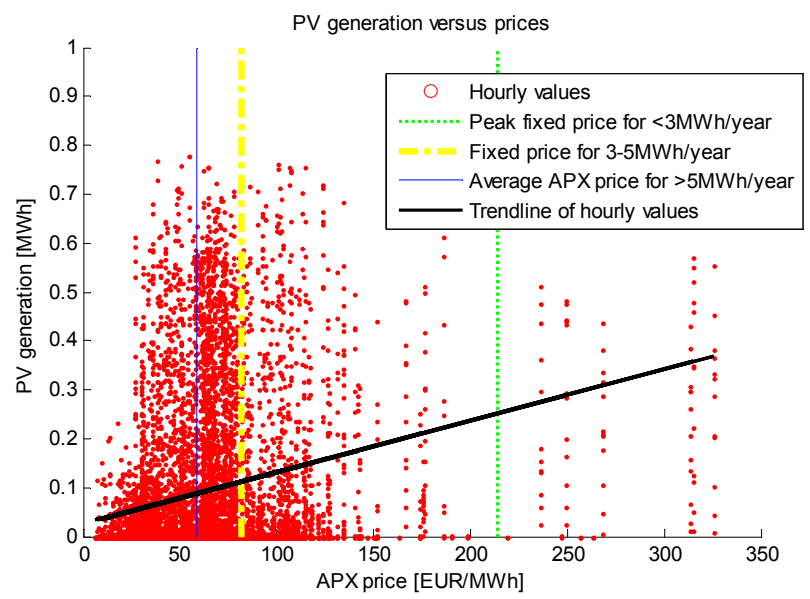

Fig. 4. PV generation versus APX day ahead market clearing price based on data of the year 2006 .

The APX prices over the whole year are displayed in Fig. 5. Since PV generates electricity during daytime, which is usually the peak period at peak price in power market, the average peak APX price should be considered as well.

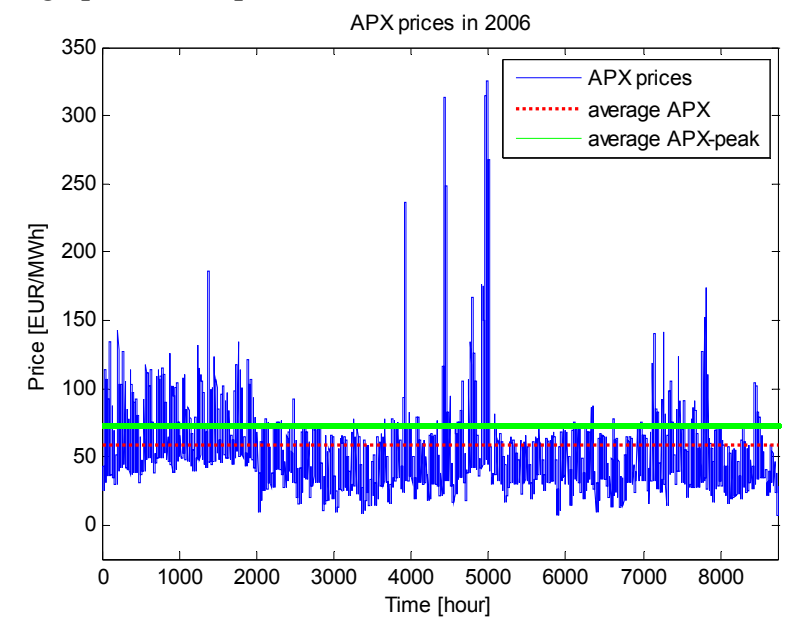

Fig. 5. APX day ahead market clearing prices in 2006. 


\section{Penalty Cost}

A 200 loops Monte Carlo simulation of full year calculation is used to generate randomly non-delivered energy and to calculate the penalty prices. The penalty prices are shown in Fig. 6.

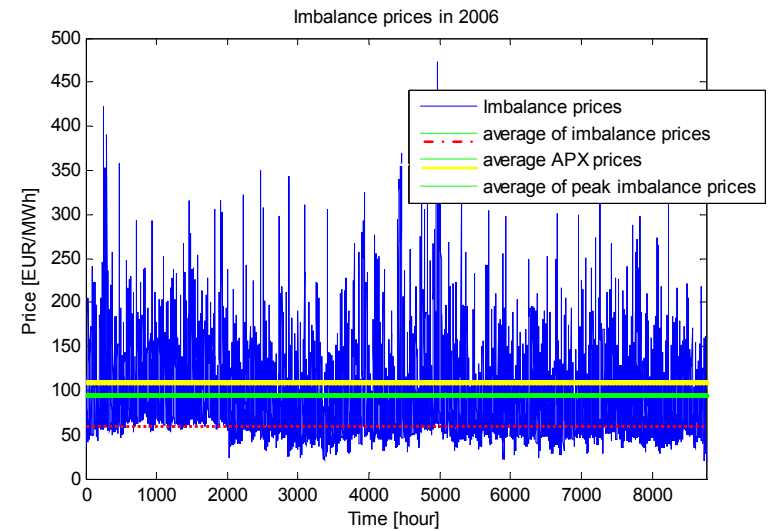

Fig. 6. Penalty prices for imbalance in 2006.

The expected yearly penalty costs with the Monte Carlo method are displayed in Fig. 7. The average penalty costs are $5167.10 € /$ year when uncertainty of PV day ahead prediction is at $30 \%$.

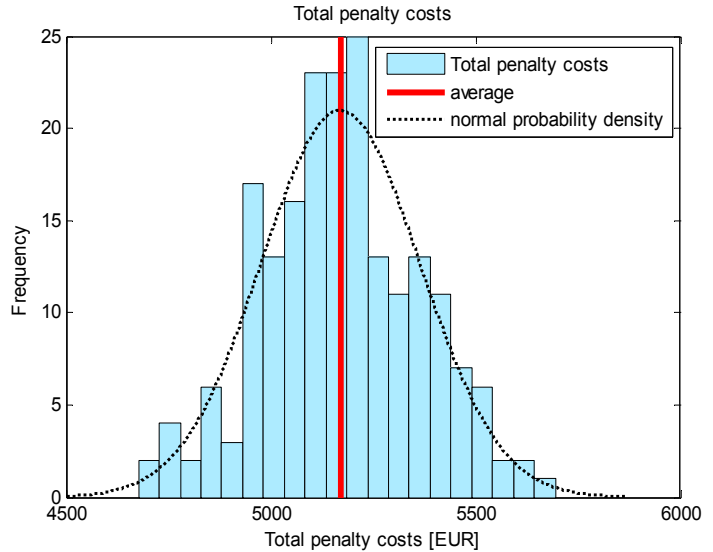

Fig. 7. Expected penalty costs due to uncertainties in the day ahead predictions of $\mathrm{PV}$ generation.

\section{Revenue Comparison}

The fixed price revenue and APX revenue of the standardized neighborhood are displayed in Fig. 8.

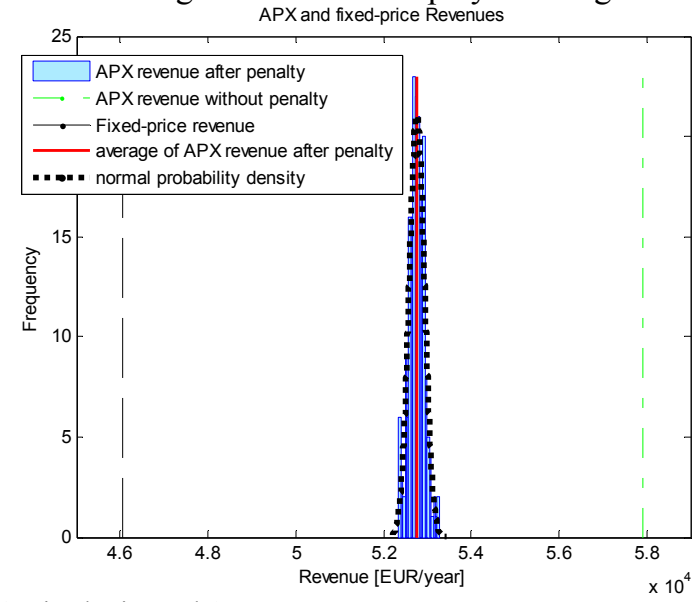

Fig. 8. Fixed price and APX revenues.
The revenue received from APX is the subtraction of the APX revenue and the yearly penalty costs (bars with the normal probability density curve in dot line), and the expectation of the APX revenue after penalty is $52.76 \mathrm{k} € /$ year (solid line) at the unpredictability of $30 \%$, which remains higher than the fixed price revenue at $46.04 \mathrm{k} € /$ year (dashed line).

\section{E. Scale Sensitivity}

As the result of the simulation, the maximum generation at which fixed price delivery is more beneficial than APX bidding is $48.50 \mathrm{MWh} /$ year. Assuming that the whole installed PV capacity in the Netherlands, which is $53.30 \mathrm{MWp}$ in 2007 [5] and generates $58.63 \mathrm{GWh} /$ year, is integrated to become one large-scale virtual power plant the possible maximum revenue difference is found to be $548 \mathrm{k} € /$ year (Fig. 9).

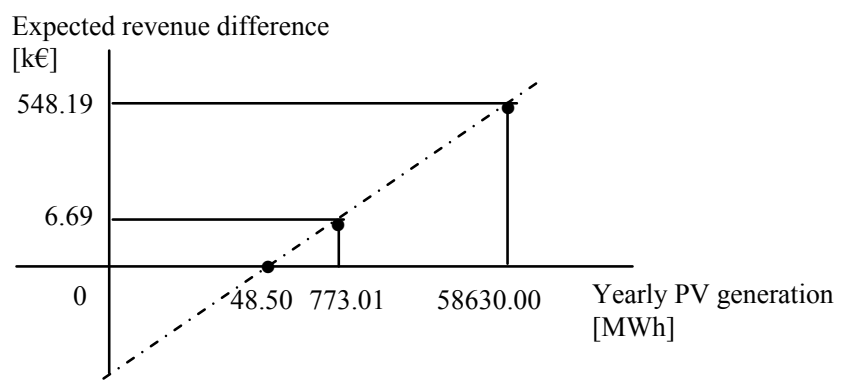

Fig. 9. Difference between APX revenue after penalty and fixed price revenue vs. PV generation.

\section{F. Unpredictability Sensitivity}

Fig. 10 shows the increasing penalty costs with increasing unpredictability, thus causing a reduction in APX revenues after subtracting the penalty. When the unpredictability is 0 , which means PV generation is exactly forecasted, the expected APX revenue is $57.93 \mathrm{k} €$. When PV generation is totally unpredictable, the expected APX revenue is $41.75 \mathrm{k} €$. When the unpredictability is greater than $68 \%$ the APX revenue after penalty is less than the fixed price revenue.

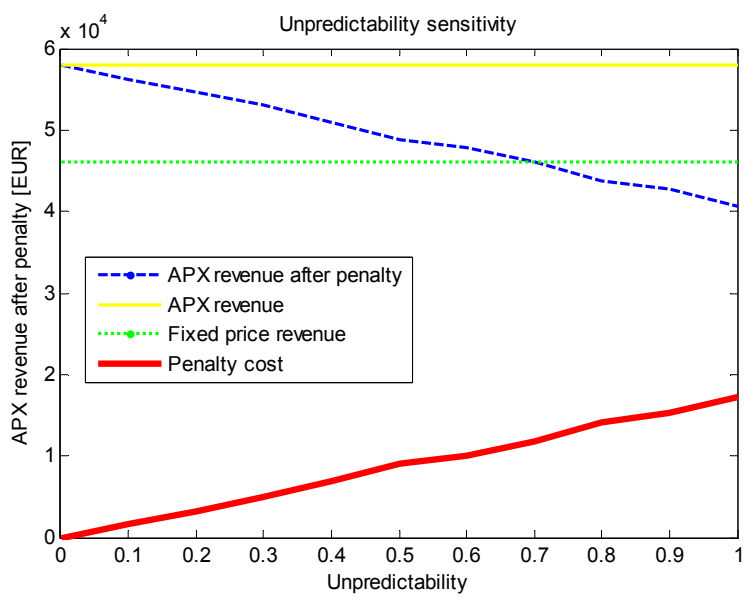

Fig. 10. Unpredictability sensitivity. 


\section{G. Different Bidding Strategies}

With reference to Fig. 5 and Fig. 6, the penalty prices are almost higher than the APX prices at all time. Therefore, it is expected that it will be more beneficial to avoid penalty costs by applying different bidding strategies, which are reducing the bidding energy at the estimated uncertainty levels.

However, the simulation result is different, the less energy is bid the less revenue is earned due to the small random numbers used as non-delivered energy. When non-delivered energy is comparable to the bidding energy lost, different bidding strategies can be more beneficial by losing revenue from APX market (normally with low price) but avoiding higher penalty costs (with high penalty prices).

Fig. 11 shows the changes in bidding energy and nondelivered energy when the bidding levels from $50 \%$ to $100 \%$ of the PV generating capacity, and Fig. 12 shows the corresponding revenues.

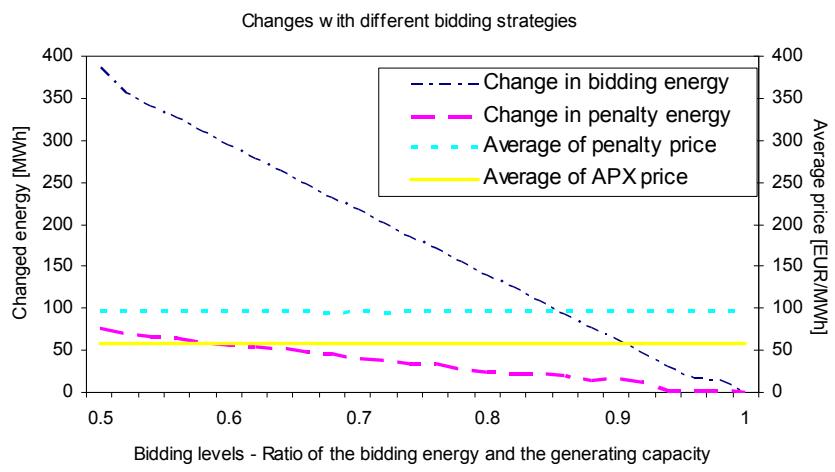

Fig. 11. Changes in bidding generation and non-delivered energy with different bidding strategies

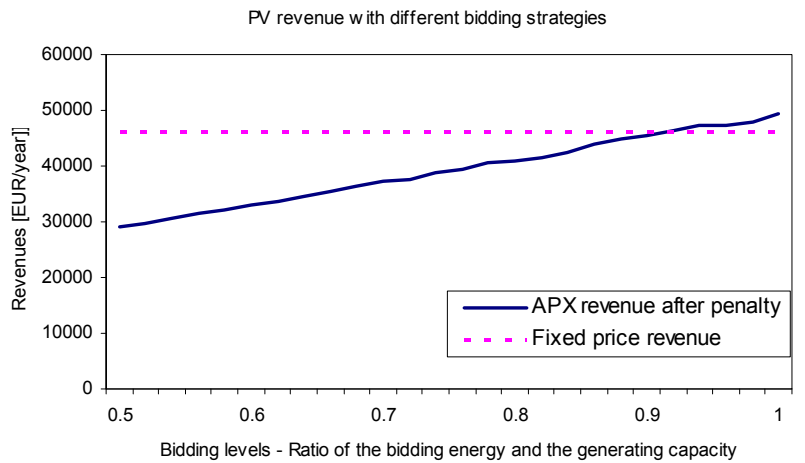

Fig. 12. Revenues with different bidding strategies

\section{CONCLUSIONS}

In this paper, an economic model for profit maximization for PV generation when joining power markets is proposed. Moreover, a simplified model is applied to simulate PV biddings in the Amsterdam Power Exchange (APX) market with a standardized neighborhood of PV generation data from the year 2006 in the Netherlands. Monte Carlo method is used to calculate the possible penalty costs of PV generation. As the result, it is more beneficial for PV generation to join APX day ahead market than to supply at fixed price when the produced electricity energy approximately is greater than $48.50 \mathrm{MWh} /$ year, corresponding to $44.09 \mathrm{kWp}$ of installed capacity. The larger the PV generation is, the more the benefit becomes.

An analysis of the sensitivity for the unpredictability is done by simulation and shows almost no difference between APX revenue after penalty and the fixed price revenue when the unpredictability is larger than $68 \%$.

Different bidding strategies of reducing bidding generation are suggested to avoid penalty costs. Further research is required for quantifying the effects of verifying bidding strategies.

\section{ACKNOWLEDGEMENTS}

We would like to thank APX (Amsterdam Power Exchange) for the provision of the APX market clearing prices of the year 2006 .

\section{REFERENCES}

[1] K. Agovic, A. Jokic, P.P.J van den Bosch, Dispatching Power and Ancillary Services in Autonomous Network-based Power Systems, 2005 International Conference on Future Power Systems, IEEE.

[2] H.Y. Yamin, A Novel Stochastic Model for the GenCos Self-scheduling in a Restructured Electricity Market, Universities Power Engineering Conference - 2007, UPEC 2007, Proceedings of the 42nd International, IEEE.

[3] J. Frunt, Effects of further integration of Distributed Generation on the Electricity market, Universities Power Engineering Conference - 2006, UPEC 2006, Proceedings of the 41st International, IEEE.

[4] Essent website http://www.essent.nl/ retrieved August 31st, 2008.

[5] J. Swens, National Survey Report of PV Power Applications in The Netherlands 2006, IEA - PVPS Program - NSRs for The Netherlands, May 2007.

\section{BIOGRAPHIES}

Dieu T. Ho was born in Ho Chi Minh city, Vietnam, in 1979. She received her B. degree in electrical and electronics engineering from Ho Chi Minh city University of Technology in 2002. She worked for Southern Vietnam Power Project Management Board in 2003 and 2006, and studied for her M.Eng degree in electrical power system management from Asian Institute of Technology, Thailand in 2004 and 2005. She joined BP in 2007. Currently she is persuing her second master degree, a M.Sc. in sustainable energy technology, at Eindhoven University of Technology, the Netherlands.

Jasper Frunt was born in 's-Hertogenbosch in 1981. He received his B. degree in electrical engineering in 2003 from the University of Professional Education in 's-Hertogenbosch. In 2006 he received his M.Sc. degree in sustainable energy technology from Eindhoven University of Technology. For his graduation projects he worked with Kema N.V. and Tennet TSO bv (Dutch Transmission System Operator) respectively. Currently he is a $\mathrm{PhD}$ in the EOS (Energy Research Subsidy) project 'Regelduurzaam' for Eindhoven University of Technology. His research focuses on current and future deployment, legislation and organization of control power for balance management.

Johanna M. A. Myrzik was born in Darmstadt, Germany in 1966. She received her MSc. in Electrical Engineering from the Darmstadt University of Technology, Germany in 1992. From 1993 to 1995 she worked as a researcher at the Institute for Solar Energy Supply Technology (ISET e.V.) in Kassel, Germany. In 1995 Johanna joined to the Kassel University, where she finished her $\mathrm{PhD}$ thesis in the field of solar inverter topologies in 2000. Since 2000, Johanna is with the Eindhoven University of Technology. In 2002 she became an assistant professor and since 2008 she is an associate professor in the field of residential electrical infrastructure and distributed generation. Her fields of interests are: power electronics, renewable energy, distributed generation, electrical power supply. 